\title{
Non-malignant consequences of decreasing asbestos exposure in the Brazil chrysotile mines and mills
}

\author{
E Bagatin, J A Neder, L E Nery, M Terra-Filho, J Kavakama, A Castelo, V Capelozzi, A Sette, \\ S Kitamura, M Favero, D C Moreira-Filho, R Tavares, C Peres, M R Becklake
}

Occup Environ Med 2005;62:381-389. doi: 10.1136/oem.2004.016188

See end of article for authors' affiliations

Correspondence to: Dr E Bagatin Occupational Health Area, State University of Campinas (UNICAMP), Av Vital Brasil, 100-CIPOI-3 piso, Cidade Universitária "Zeferino Vaz",

Campinas, São' Paulo, Brazil; ebagatin@aso.fcm. unicamp.br

Accepted

15 December 2004
Aims: To investigate the consequences of improvement in the workplace environment over six decades (1940-96) in asbestos miners and millers from a developing country (Brazil).

Methods: A total of 3634 Brazilian workers with at least one year of exposure completed a respiratory symptoms questionnaire, chest radiography, and a spirometric evaluation. The study population was separated into three groups whose working conditions improved over time: group I (1940-66, $n=180)$, group II (1967-76, $\mathrm{n}=1317$ ), and group III (1977-96, $\mathrm{n}=2137$ ).

Results: Respiratory symptoms were significantly related to spirometric abnormalities, smoking, and latency time. Breathlessness, in particular, was also associated with age, pleural abnormality and increased cumulative exposure to asbestos fibres. The odds ratios (OR) for parenchymal and/or nonmalignant pleural disease were significantly lower in groups II and III compared to group I subjects (0.29 $(0.12-0.69)$ and $0.19(0.08-0.45)$, respectively), independent of age and smoking status. Similar results were found when groups were compared at equivalent latency times (groups I $v$ II: 30-45 years; groups II $v$ III: 20-25 years). Ageing, dyspnoea, past and current smoking, and radiographic abnormalities were associated with ventilatory impairment. Lower spirometric values were found in groups I and II compared to group III: lung function values were also lower in higher quartiles of latency and of cumulative exposure in these subjects.

Conclusions: Progressive improvement in occupational hygiene in a developing country is likely to reduce the risk of non-malignant consequences of dust inhalation in asbestos miners and millers.
A sbestos inhalation has been frequently associated with structural and respiratory functional abnormalities. ${ }^{12}$ Control of exposure is of paramount importance to reduce its deleterious effects. Asbestosis still constitutes a major occupational health problem, especially for developing countries, such as Brazil, where effective control of exposure has been achieved only recently. ${ }^{3}$ A number of previous studies have shown that asbestos mining and milling increases the probability of asbestosis and pleural abnormalities, with variable consequences on lung function..$^{4-9}$ Brazil is the world's fifth leading producer of asbestos. Large scale mining and milling activities started in the country in the early 1940s. A single company has been in charge of asbestos exploration in Brazil: from 1940 to 1967 in the Northeast State of Bahia and, thereafter, in the Central State of Goias. According to reports from the company and the union workers, a programme aiming to monitor exposure and health was introduced in the Goias' mine starting in 1967 (as detailed in Methods). To the authors' knowledge, no previous study has specifically looked at the long term effects of improving environmental work conditions in a large cohort of miners and millers from a developing country. This communication, therefore, deals with the first epidemiological study aimed to evaluate the relation between radiographic evidence of parenchymal and/or pleural disease and clinical and lung function abnormalities, as modulated by progressive improvement in occupational exposure, in Brazilian chrysotile asbestos miners and millers.

\section{METHODS}

Study design and subjects

This was a retrospective study. The study population consisted of all workers and ex-workers of a single asbestos mining and milling company (Sociedade Mineradora de Amianto SA) who had worked for at least one year for the company. This timeframe was chosen because shorter periods of time are rarely associated with development of a measurable respiratory risk. ${ }^{10}$ From the start of the company's operation (1940) to the date of study commencing (1996), 6098 subjects were found to fulfil this criterion. A list of these subjects was made available to the investigators by the company. During a four year period, a multi-institutional effort, which included local municipalities and union workers, was responsible for recruiting the subjects who participated in the study.

Asbestos mining and milling in Brazil covers three time periods: (a) from 1940 to 1967 in the São Félix mine (State of Bahia, Northeast Region), where no measurements of exposure and/or control of exposure were operational and tremolite was found in association with chrysotile $(\mathrm{n}=538) ; ;^{11}$ (b) from 1967 to 1976 in the Canabrava mine (State of Goiás, Central Region) where no evidence of amphyboles has been found $(\mathrm{n}=2134) ;^{12}$ and (c) from 1977 to 1996 when routine fibre measurements and a comprehensive programme of controlled chrysotile exposure were operational in the Canabrava mine $(n=3426)$. Based on the differences in quality and intensity of asbestos exposure in the three time periods listed above, the study population was stratified into three historical groups (I, II, and III). Subjects who started working in the Canabrava mine before 1977 were included in group II, irrespective whether they remained working in the mine after this time.

Informed consent for participation in the study was obtained from all subjects, and the study protocol was approved by the Medical Ethics Committee of the Campinas State University (UNICAMP), Sao Paulo, Brazil. 


\section{Main messages}

- The risk of non-malignant lung abnormalities and lung function impairment declined significantly over time as asbestos exposure was progressively reduced in Brazilian mines and mills.

- The negative consequences of smoking were particularly evident in the younger subjects who were the least exposed.

- Respiratory symptoms were independently associated with lung function impairment, current or past smoking, higher cumulative exposure, longer latency time, ageing, and pleural abnormality.

- Cumulative exposure, latency time, smoking and combined pleural and parenchymal abnormalities were independent predictors of lung function decline.

- The risk of an obstructive ventilatory defect was higher in subjects presenting with combined parenchymal and pleural alterations than those with isolated parenchymal abnormalities.

\section{Measurements}

Occupational and smoking history

A standardised occupational history was administered by interview, detailing the start and end of exposure, the specific workplace(s), and the estimated level of exposure (groups I and II, see below). "Latency" was defined as the time period elapsed since the time of first exposure to the time of the health examination. Subjects were also asked about their smoking history, and were classified as never smokers, exsmokers (smoking cessation at least one year before examination), and current smokers.

The presence of dyspnoea was recorded in all subjects by means of a Medical Research Council (MRC) questionnaire translated into Portuguese. ${ }^{13}$ In addition, presence of other respiratory symptoms (wheezing, phlegm, and cough) was also established.

\section{Exposure}

Because there were no systematic fibre measurements in the plants before 1976, a subjective, logarithmic scale was developed to estimate indices of dust exposure for subjects in groups I and II. Fibre measurements performed before the start of the exposure control programme were used to establish three broad levels of workplace dustiness (mild $=$ from 0.3 to 3 fibres/cubic $\mathrm{cm}$ (cc), moderate $=$ from 3 to 30.0 fibres $/ \mathrm{cc}$, and severe $=$ more than 30 fibres $/ \mathrm{cc}$ ). These levels were colour coded on a questionnaire as green, white, and red, respectively. Subjects were asked to indicate the colour type and intensity that corresponded best to the average level of dust exposure in their workplaces, from "no dust at all" $=$ dark green, to "very dusty" $=$ dark red. ${ }^{14}$

After 1976 (group III), measurements of asbestos fibres in the occupational setting were routinely performed (fig 1). Airborne samples were obtained from different areas of activity in the mining and milling processes, using a constant-flow sampler. Fibre counting was performed according to the National Institute of Occupational Safety and Health standards: a membrane filter was used to collect the fibres and the counting was done with a phase contrast microscope. ${ }^{15}$ Briefly, the exposure control programme included: the introduction of a widespread air filtering, dust collection, humidification, use of individual protection devices, and automatic handling and packing of the milled asbestos. An index of the workers' asbestos exposure was

\section{Policy implications}

- Progressive improvement in occupational hygiene in mines and mills is likely to markedly reduce the risk of non-malignant consequences of dust inhalation in miners and millers exposed mainly to chrysotile.

- Asbestos workers with combined pleural and parenchymal abnormalities should be evaluated for early detection of lung function impairment.

- Large scale anti-smoking strategies are warranted in asbestos mines and mills.

calculated assuming that the cumulative amount of asbestos exposure in the lungs was proportional to intensity and duration of the inhalation "load" for each job ever held (cumulative exposure in fibres/year/cc).

\section{Radiographic evaluation}

Standard high-kilovoltage, posteroanterior chest radiographs were performed at a single centre before the physiological evaluation. Radiographs were classified by three chest physicians up to September 1999 (two B-readers and one A-reader) - that is, each film was read by multiple readers. After this date, one of the B-readers was replaced on the panel by a radiologist with 18 years' experience. The readers were blinded to the group to which the worker belonged. Radiographs were interpreted according to the International Labour Office (ILO) Classification of Radiographs of Pneumoconiosis. ${ }^{16}$ For the present study, parenchymal opacities were reported if the ILO reading was $1 / 0$ or more: occasional disagreement was sorted out by consensus. Recorded profusion readings were the median values. Presence of pleural plaques was also established.

\section{Spirometry}

Spirometric tests were performed with a calibrated pneumotacograph (Fleisch No. 3). The subjects completed at least three acceptable maximal forced expiratory manoeuvres: technical procedures, acceptability, and reproducibility criteria were those recommended by the American Thoracic Society. ${ }^{17}$ The following variables were recorded and expressed as: body temperature, ambient pressure, saturated with water vapour (BTPS): forced vital capacity (FVC, l), forced expiratory volume in one second $\left(\mathrm{FEV}_{1}, \mathrm{l}\right), \mathrm{FEV}_{1} / \mathrm{FVC}$ ratio, and forced expiratory flow between $25 \%$ and $75 \%$ of the

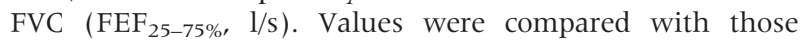
predicted from Pereira et al for the adult Brazilian population: ${ }^{18}$ these regression equations consider age, gender, and height. In these equations, the limits for normality are defined according to the one sided $95 \%$ confidence interval around the predicted value. An obstructive ventilatory defect was defined as a reduced $\mathrm{FEV}_{1}$ (below the lower limit of normality) and $\mathrm{FEV}_{1} / \mathrm{FVC}$ ratio $(<0.7)$, with $\mathrm{FVC}$ values above the lower limit of normality. A restrictive ventilatory defect was defined as reduced FVC with normal $\mathrm{FEV}_{\mathrm{l}} / \mathrm{FVC}$.

\section{Data analysis}

Analyses were performed with SPSS for Windows 10.0 statistical software package (SPSS Inc., Chicago, IL, USA). Data for which the distribution was normal are reported as mean values and standard deviations (SD). One way ANOVA was used to determine differences in subjects separated by groups of exposure: post-hoc Scheffé test was used when appropriate. Non-paired Student's $t$ test was used to compare groups of exposure at the equivalent latency times. Differences in proportions were assessed by $\chi^{2}$ tests. 

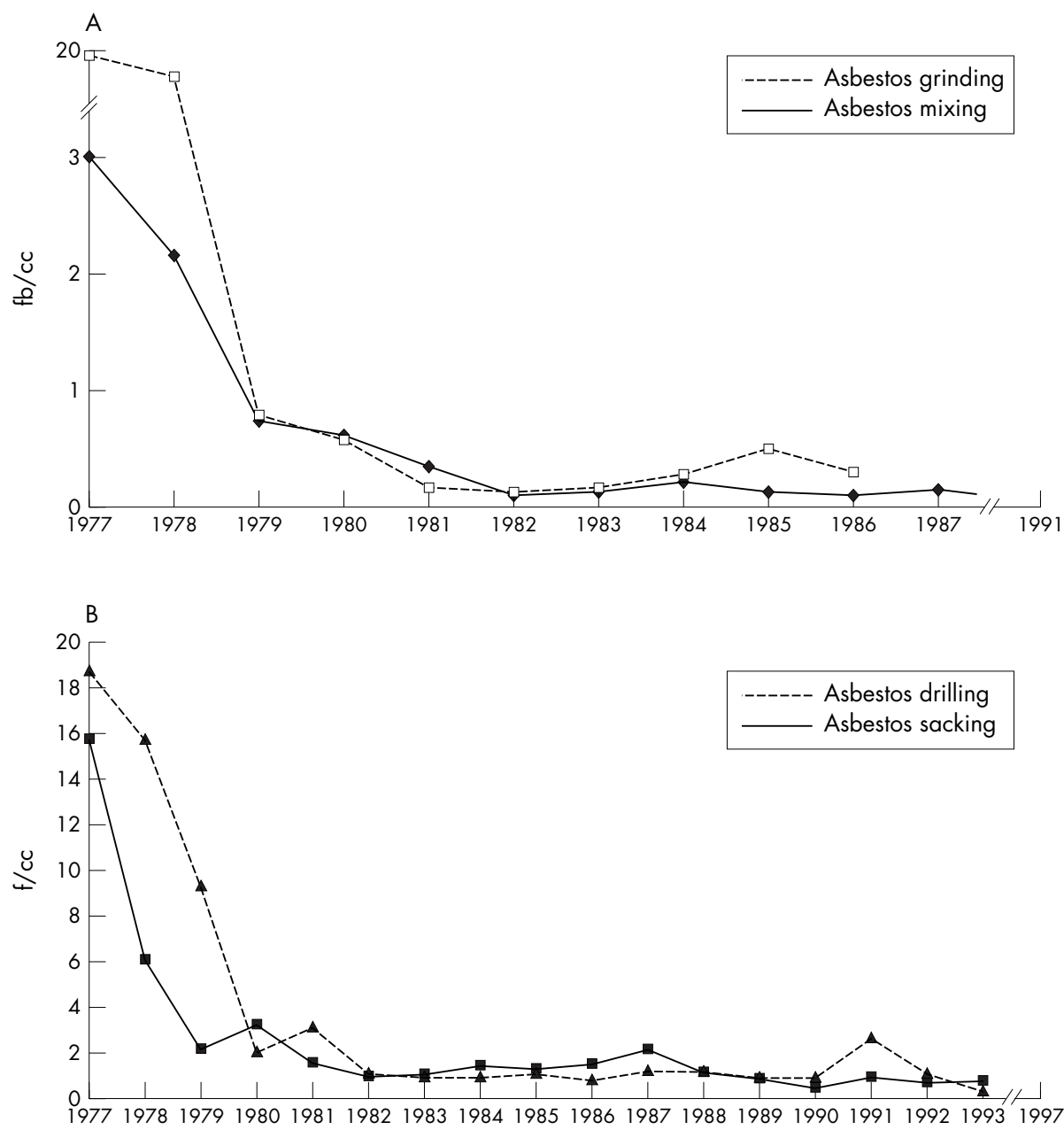

Figure 1 Annual decline on fibre concentrations in the Canabrava mine (Central Brazil) since 1976. Concentration readings were obtained at different locations in the mine.

Stepwise multiple logistic regression analysis was performed with clinical, radiographic, and lung function abnormalities as the dependent variables. Interaction terms between the independent variables were also considered for model inclusion. Parameters known to be associated with the outcomes of interest (latency and smoking) remained in the final model at a level of significance of 0.15; for the other variables, a p value of 0.05 was used. Considering the high degree of collinearity between age and most of the variables of interest, this parameter was allowed to remain in the final models independently of its level of statistical significance.

The effect of exposure group, cumulative exposure, and latency time on the spirometric variables were analysed using a modified life table procedure. In this method, the cumulative "survival" of spirometric scores was compared using the Wilcoxon test. ${ }^{19}$ A backward stepwise linear regression procedure was also used for analysing the relation of the spirometric variables to latency, cumulative exposure, smoking (pack-years), and radiographic abnormalities. Probability of type I error was established at 0.05 for all tests.

Informed consent for participation in the study was obtained from all subjects, and the study protocol was approved by the Medical Ethics Committee of the Campinas State University (UNICAMP), Sao Paulo, Brazil.

\section{RESULTS}

Population characteristics

From the 6098 eligible subjects, 433 (7.1\%) were found to be dead (148, 184, and 101 subjects for groups I, II, and III, respectively); 3634 of the remaining 5665 were actually examined $(64.1 \%)$. The rate of recruitment success varied between the different groups: group $\mathrm{I}=46.1 \% \quad(180 / 390$ alive), group II $=67.5 \%$ (1317/1950), and group III $=64.2 \%$ (2137/3325) (table 1).

The demographic and occupational variables differed significantly among the groups. Thus, group III subjects were younger and presented with a shorter latency than their counterparts of groups I and II (table 1); the median values for latency time were: 42.5 years, 24.8 years, and 18.7 years, for groups I to III, respectively. Higher cumulative exposure was also found in group I subjects compared to groups II and III; the median values for cumulative exposure for groups I to III were: 51.2, 20.2, and 2.4 fibre/y/cc, respectively.

\section{Clinical findings}

Current or past smoking history was reported by $75.6 \%$ of group I subjects (table 1): 18.9\% (34/180) of these patients smoked more than 50 pack-years compared to $7.0 \%$ (92/ 1317 ) and $2.7 \%$ (58/2137) of group II and III subjects. There was a significant association of smoking with obstructive 
Table 1 Population characteristics according to groups of asbestos exposure

\begin{tabular}{|c|c|c|c|}
\hline Variables & Group I $(n=180)$ & Group II $(n=1317)$ & Group III $(n=2137)$ \\
\hline \multicolumn{4}{|l|}{ Demographic/anthopometric } \\
\hline Age (years) & $64.9 \pm 8.4$ & $51.1 \pm 7.9^{*}$ & $41.3 \pm 9.5^{\star *}$ \\
\hline Body mass index $\left(\mathrm{kg} / \mathrm{m}^{2}\right)$ & $25.3 \pm 4.1$ & $26.3 \pm 4.2$ & $25.7 \pm 3.9$ \\
\hline \multicolumn{4}{|l|}{ Occupational exposure } \\
\hline Latency (years) & $43.7 \pm 7.0$ & $25.9 \pm 3.6^{*}$ & $15.9 \pm 5.8^{* *}$ \\
\hline Exposure (years) & $12.9 \pm 10.7$ & $10.1 \pm 7.2^{*}$ & $7.5 \pm 3.2^{* *}$ \\
\hline Cumulative exposure (fibre/y/cc) & $109.1 \pm 141.9$ & $39.4 \pm 50.4^{*}$ & $4.3 \pm 5.9^{* *}$ \\
\hline \multicolumn{4}{|l|}{ Clinical findings } \\
\hline Current or past smoking (\%) & 75.6 & 63.7 & 49.6 \\
\hline Smoking (pack-years) & $33.1 \pm 56.5$ & $14.5 \pm 22.4^{*}$ & $8.4 \pm 17.0^{* *}$ \\
\hline \multicolumn{4}{|l|}{ Symptom prevalence } \\
\hline Dyspnoea (\%) & 17.8 & 30.3 & $15.3 \dagger$ \\
\hline Wheezing (\%) & 7.8 & 15.9 & $6.9+$ \\
\hline Cough $(\%)$ & 16.1 & 22.4 & $10.8+$ \\
\hline Phlegm (\%) & 10.6 & 14.1 & $7.5+$ \\
\hline \multicolumn{4}{|l|}{ Radiographic abnormalities } \\
\hline Parenchymal (1/0 or greater, \%) & 9.5 & 2.7 & $0.8 \dagger$ \\
\hline $1 / 0(\%)$ & 5.0 & 1.5 & 0.6 \\
\hline $1 / 1(\%)$ & 3.9 & 0.5 & 0.2 \\
\hline $1 / 2$ or greater $(\%)$ & 0.6 & 0.7 & - \\
\hline Pleural (\%) & 16.1 & 4.0 & $1.7 \dagger$ \\
\hline Pleural and/or parenchymal (\%) & 22.2 & 6.0 & $2.5 \dagger$ \\
\hline \multicolumn{4}{|l|}{ Lung function abnormalities } \\
\hline FVC (\% pred) & $94.4 \pm 17.3$ & $102.5 \pm 17.41^{*}$ & $106.0 \pm 14.9^{* *}$ \\
\hline $\mathrm{FEV}_{1}(\%$ pred $)$ & $91.0 \pm 20.0$ & $97.2 \pm 18.2^{*}$ & $100.7 \pm 15.7^{* *}$ \\
\hline $\mathrm{FEV}_{1} / \mathrm{FVC}(\%)$ & $70.1 \pm 7.1$ & $72.2 \pm 7.3^{*}$ & $74.2 \pm 7.1^{* *}$ \\
\hline $\mathrm{FEF}_{25-75 \%}(\%$ pred $)$ & $77.2 \pm 39.3$ & $85.8 \pm 39.1^{*}$ & $83.0 \pm 38.8$ \\
\hline Abnormal spirometry (\%) & 29.8 & 24.5 & 20.0 \\
\hline Obstructive (\%) & 82.3 & 80.1 & 88.8 \\
\hline Restrictive (\%) & 11.7 & 18.6 & 9.9 \\
\hline Combined (\%) & 7.0 & 1.3 & 1.3 \\
\hline \multicolumn{4}{|c|}{$\begin{array}{l}\text { Number of recruited/eligible subjects alive: group I= 180/390 (46.1\%); group II = 1317/1950 (67.5\%); and } \\
\text { group III = } 2137 / 3325(64.2 \%) \text {. } \\
\text { p<0.05: }{ }^{*} \text { group II } v \text { I and III; }{ }^{* *} \text { group III } v \text { I and II (ANOVA). } \\
\dagger \chi^{2} \text { analysis. }\end{array}$} \\
\hline
\end{tabular}

Table 2 Final logistic regression models for symptoms

\begin{tabular}{|c|c|c|}
\hline & Logit coefficient (SE) & Odds ratio $(95 \% \mathrm{Cl})$ \\
\hline \multicolumn{3}{|l|}{ Dyspnoea* } \\
\hline Restrictive defect & $0.94(0.21)$ & 2.57 (1.68 to 3.91$)$ \\
\hline Obstructive defect & $0.59(0.10)$ & $1.80(1.48$ to 2.20$)$ \\
\hline Current or past smoking & $0.51(0.09)$ & $1.67(1.39$ to 1.99$)$ \\
\hline Pleural abnormality & $0.41(0.21)$ & 1.50 (1.01 to 2.21$)$ \\
\hline Cumulative exposure $\geqslant 10$ fibres $/ y / c c$ & $0.38(0.09)$ & $1.47(1.23$ to 1.75$)$ \\
\hline Age over 50 years & $0.36(0.12)$ & $1.43(1.11$ to 1.84$)$ \\
\hline Constant & $-2.03(0.08)$ & \\
\hline \multicolumn{3}{|l|}{ Wheezing } \\
\hline Obstructive defect & $0.95(0.12)$ & 2.59 (2.04 to 3.30$)$ \\
\hline Restrictive defect & $0.92(0.26)$ & $2.52(1.49$ to 4.27$)$ \\
\hline Current or past smoking & $0.57(0.12)$ & $1.77(1.38$ to 2.25$)$ \\
\hline Latency over 20 years & $0.03(0.006)$ & $1.03(1.02$ to 1.04$)$ \\
\hline Constant & $-3.53(0.16)$ & \\
\hline \multicolumn{3}{|l|}{ Cough } \\
\hline Restrictive defect & $0.93(0.23)$ & 2.54 (1.59 to 4.05$)$ \\
\hline Obstructive defect & $0.81(0.11)$ & $2.26(1.82$ to 2.80$)$ \\
\hline Current or past smoking & $0.48(0.10)$ & $1.63(1.32$ to 2.00$)$ \\
\hline Latency over 20 years & $0.04(0.005)$ & $1.04(1.03$ to 1.05$)$ \\
\hline Constant & $-3.23(0.14)$ & \\
\hline \multicolumn{3}{|l|}{ Phlegm } \\
\hline Obstructive defect & $0.87(0.12)$ & 2.40 (1.87 to 3.07$)$ \\
\hline Current or past smoking & $0.74(0.13)$ & $2.10(1.62$ to 2.72$)$ \\
\hline Restrictive defect & $0.70(0.29)$ & 2.01 (1.13 to 3.59$)$ \\
\hline Latency over 20 years & $0.03(0.006)$ & $1.03(1.02$ to 1.04$)$ \\
\hline Constant & $-3.72(0.17)$ & \\
\hline \multicolumn{3}{|c|}{$\begin{array}{l}{ }^{*} M R C \text { questionnaire. } \\
\text { The following variables were considered for model inclusion: age ( }>50 \text { years), group of exposure, obstructive and } \\
\text { restrictive impairments, radiographic abnormalities, cumulative exposure ( } \geqslant 10 \text { fibres/y/cc), latency ( } \geqslant 20 \text { years), } \\
\text { and smoking (current or past). }\end{array}$} \\
\hline
\end{tabular}


Table 3 Final logistic regression models for radiographic abnormalities

\begin{tabular}{|c|c|c|}
\hline & Logit coefficient (SE) & Odds ratio $(95 \% \mathrm{Cl})$ \\
\hline \multicolumn{3}{|l|}{ Parenchymal abnormalities } \\
\hline Age $>50$ years & $1.86(0.25)$ & 6.47 (3.89 to 10.75$)$ \\
\hline Cumulative exposure $\geqslant 10$ fibres/y/cc & $1.10(0.28)$ & $3.02(1.72$ to 5.31$)$ \\
\hline Current or past smoking & $0.39(0.27)$ & $1.48(0.86$ to 2.56$)$ \\
\hline Constant & $-5.30(0.29)$ & \\
\hline \multicolumn{3}{|l|}{ Pleural abnormalities } \\
\hline Age $>50$ years & $1.24(0.24)$ & $3.48(2.16$ to 5.60$)$ \\
\hline Cumulative exposure $\geqslant 10$ fibres $/ y / c c$ & $0.36(0.24)$ & $1.44(0.89$ to 2.33$)$ \\
\hline Current or past smoking & $0.31(0.21)$ & $1.36(0.90$ to 2.06$)$ \\
\hline Group $\|^{*}$ & $-0.70(0.28)$ & $0.49(0.28$ to 0.86$)$ \\
\hline Group III* & $-1.10(0.36)$ & $0.33(0.16$ to 0.67$)$ \\
\hline Constant & $-3.24(0.38)$ & \\
\hline \multicolumn{3}{|l|}{ Pleural and/or parenchymal abnormalities } \\
\hline Age $>50$ years & $1.37(0.20)$ & 3.95 (2.66 to 5.87$)$ \\
\hline Group II* and cumulative exposure $\geqslant 10$ fibres/y/cc & $0.75(0.44)$ & $2.12(0.88$ to 5.10$)$ \\
\hline Group $\| l^{*}$ and current or past smoking & $0.73(0.37)$ & $2.07(0.99$ to 4.30$)$ \\
\hline Cumulative exposure $\geqslant 10$ fibres/y/cc & $0.19(0.31)$ & $1.21(0.66$ to 2.22$)$ \\
\hline Current or past smoking & $0.09(0.21)$ & $1.10(0.72$ to 1.68$)$ \\
\hline Group $\|^{*}$ & $-1.24(0.45)$ & $0.29(0.12$ to 0.69$)$ \\
\hline Group III* & $-1.66(0.42)$ & $0.19(0.08$ to 0.45$)$ \\
\hline Constant & $-2.62(0.39)$ & \\
\hline \multicolumn{3}{|c|}{$\begin{array}{l}\text { *Compared to Group I. } \\
\text { The following variables were considered for model inclusion: age ( }>50 \text { years), group of exposure, obstructive and } \\
\text { restrictive impairments, cumulative exposure ( } \geqslant 10 \text { fibres/y/cc), latency ( } \geqslant 20 \text { years), and smoking (current or } \\
\text { past). }\end{array}$} \\
\hline
\end{tabular}

impairment and dyspnoea in all groups $\left(\mathrm{p}<0.05, \chi^{2}\right.$ test, data not shown).

Twenty one per cent of the workers reported breathlessness on daily activities. ${ }^{12}$ The prevalence of dyspnoea was lowest in group III (table 1). This symptom was independently associated with lung function impairment (both restrictive and obstructive), current or past smoking, cumulative exposure $(\geqslant 10$ fibre $/ \mathrm{y} / \mathrm{cc})$, and age over 50 years $(\mathrm{p}<0.05$, Table 2 ). In addition, pleural abnormalities were independent predictors of subjective impairment (table 2).

Wheezing, cough, and phlegm were found in $10.9 \%, 14.9 \%$, and $10.1 \%$ of the groups, respectively (data not shown). As with dyspnoea, prevalence of these symptoms tended to be lower in group III, compared to groups I and II (table 1). As shown in table 2, lung function impairment (both restrictive and obstructive), current and past smoking, and latency time (over 20 years), but not radiographic abnormalities, were independently associated with these specific outcomes $(\mathrm{p}<0.01)$.

\section{Radiographic abnormalities}

Parenchymal or pleural abnormalities ${ }^{16}$ were found in $1.9 \%$ and $3.3 \%$ of the workers and the lesions were concomitantly found in $4.7 \%$ of the population. The prevalence of these abnormalities was significantly higher in group I subjects (table 1). Most subjects presented with only minor $x$ ray alterations, even in group I subjects (table 1).

Age over 50 years was a strong independent predictor of radiographic abnormalities, especially for parenchymal alterations $(\mathrm{p}<0.01)$. Odds ratios for pleural and combined (pleural and/or parenchymal) abnormalities were significantly lower in groups II and III compared to group I subjects (table 3). Cumulative exposure equal or greater than 10 fibres/y/cc and current or previous smoking increased the event probability in all groups (table 3). Interestingly, there were interaction effects of cumulative exposure with group II and of smoking with group III for the prediction of pleural and/or parenchymal abnormalities. Thus, a higher cumulative exposure and current or previous smoking increased the risk of mixed abnormalities in group II and III subjects, respectively (table 3 ).

Considering the large differences on latency time among the three groups (table 1), we also compared the groups at similar latency ranges (groups I $v$ II $=30-45$ years and group II $v$ III $=20-25$ years). As shown in table 4, the prevalence of parenchymal or mixed (pleural and/or parenchymal) abnormalities were higher in group I compared to group II. Similarly, group II subjects presented with higher prevalence of pleural or mixed abnormalities than group III subjects with similar latency times (table 4 ).

\section{Lung function abnormalities}

One hundred and twenty one tests did not meet our quality criteria $^{17}$ and therefore they were not included in the study. Spirometric abnormalities were found in 776 subjects $(24.7 \%)$, with most of them depicting only mild obstructive impairment (data not shown). Table 5 shows that past and current smoking and radiographic abnormalities were associated with increased risk of obstructive defects; interestingly, however, smoking was related to a reduced risk of restrictive abnormalities. Ageing and dyspnoea were also independently associated with ventilatory impairment (table 5). Presence of combined pleural and parenchymal abnormalities did not enhance the likelihood of restrictive impairment compared to pleural abnormality alone (OR 2.20 (95\% CI 1.55 to 3.11 ) $v$ 3.64 (95\% CI 1.86 to 7.10 ), respectively).

Although the mean spirometric values were close to normality in all groups (tables 1 and 4), the life table analysis showed significant differences between exposure groups. FVC scores were found to be lower in group I, especially when compared to group III subjects (fig 2A). A further intra-group analysis showed a significant effect of cumulative exposure and latency in groups I and II. Therefore, the higher quartiles of exposure and latency time exhibited lower spirometric scores compared to the interquartile range or lower quartiles in these groups $(p<0.05)$. Data for FVC values are shown in figs $2 \mathrm{~B}-\mathrm{D}$ : similar results were found in relation to $\mathrm{FEV}_{1}, \mathrm{FEV}_{1} / \mathrm{FVC}$, and $\mathrm{FEF}_{25-75 \%}$ (not shown).

We also sought to determine the independent predictors of lung function impairment when the spirometric responses were expressed as continuous variables (\% predicted). As shown in table 6, latency over 25 years, current or past smoking, combined pleural and parenchymal abnormalities, and increased cumulative exposure were related to reduced spirometric values $(\mathrm{p}<0.05)$. 
Table 4 Comparison between groups of exposure at equivalent latency times from the start of exposure to health examination

\begin{tabular}{|c|c|c|c|c|}
\hline \multirow[b]{2}{*}{ Variables } & \multicolumn{2}{|c|}{$30-45$ years latency } & \multicolumn{2}{|c|}{$20-25$ years latency } \\
\hline & $\begin{array}{l}\text { Group I } \\
(n=107)\end{array}$ & $\begin{array}{l}\text { Group II } \\
(n=217)\end{array}$ & $\begin{array}{l}\text { Group II } \\
(n=713)\end{array}$ & $\begin{array}{l}\text { Group III } \\
(n=713)\end{array}$ \\
\hline \multicolumn{5}{|l|}{ Demographic/anthopometric } \\
\hline Age (years) & $61.5 \pm 7.3$ & $56.0 \pm 7.1^{*}$ & $49.1 \pm 7.8$ & $47.3 \pm 7.3^{*}$ \\
\hline Body mass index $\left(\mathrm{kg} / \mathrm{m}^{2}\right)$ & $25.3 \pm 4.3$ & $26.3 \pm 4.5^{*}$ & $26.1 \pm 4.1$ & $26.2 \pm 4.0$ \\
\hline \multicolumn{5}{|l|}{ Occupational exposure } \\
\hline Exposure (years) & $10.7 \pm 10.4$ & $10.2 \pm 8.8$ & $10.1 \pm 6.1$ & $9.7 \pm 6.8$ \\
\hline Cumulative exposure (fibre/y/cc) & $97.3 \pm 124.4$ & $63.8 \pm 78.6^{*}$ & $121.5 \pm 79.3$ & $92.9 \pm 66.3^{*}$ \\
\hline \multicolumn{5}{|l|}{ Radiographic abnormalities } \\
\hline Parenchymal (\%) & 10.3 & $3.7 \dagger$ & 2.4 & 1.3 \\
\hline Pleural (\%) & 11.2 & & 4.6 & $2.0 \dagger$ \\
\hline Pleural and/or parenchymal (\%) & 18.7 & $9.2 \dagger$ & 5.6 & $3.1 \dagger$ \\
\hline \multicolumn{5}{|l|}{ Lung function abnormalities } \\
\hline FVC (\% pred) & $97.5 \pm 17.2$ & $100.2 \pm 17.3$ & $103.4 \pm 16.9$ & $104.9 \pm 15.6^{*}$ \\
\hline $\mathrm{FEV}_{1}(\%$ pred) & $93.9 \pm 19.5$ & $94.5 \pm 20.0$ & $98.2 \pm 18.1$ & $99.2 \pm 17.1$ \\
\hline $\mathrm{FEV}_{1} / \mathrm{FVC}(\%)$ & $74.8 \pm 7.2$ & $74.7 \pm 7.5$ & $76.9 \pm 7.8$ & $77.1 \pm 7,2$ \\
\hline $\mathrm{FEF}_{25-75 \%}(\%$ pred $)$ & $81.7 \pm 40.1$ & $82.3 \pm 40.1$ & $88.5 \pm 37.5$ & $83.8 \pm 40.1^{*}$ \\
\hline
\end{tabular}

\section{DISCUSSION}

The present investigation examined the subjective and objective consequences of progressive improvement in workplace conditions in 3634 Brazilian asbestos miners and millers, the largest evaluation ever performed in this workforce. The main findings of this study were as follow: (1) respiratory symptoms were independently associated with lung function impairment (both obstructive and restrictive), current or past smoking, higher cumulative exposure, longer latency time, ageing, and pleural abnormality on chest $x$ ray; (2) prevalence of radiographic abnormality was considerably lower in subjects who worked under improved environmental conditions (groups II and III compared to group I), independent of age and smoking status; and (3) the lung function consequences of asbestos exposure were significantly less frequent in group III (not exposed to amphibole containing chrysotile) compared to group I (exposed).

Asbestos mining and milling have well characterised relations with a number of hazards for the respiratory system, ${ }^{4-9}{ }^{20-23}$ and it is intuitive to consider that reduction in exposure would be related to less morbidity. However, few studies have examined the effects of changing workplace conditions on the respiratory health of a large number of asbestos workers exposed primarily to chrysotile in a developing country. In our study, we had access to the large database of the single company responsible for asbestos mining and milling in Brazil since the early 1940s. This allowed us to evaluate the historical trends of changes in estimated exposure and the risk of development of lung structural and lung function impairment. Our results show that following the establishment of controlled exposure conditions there were reduced rates of non-malignant respiratory morbidity related to asbestos mining and milling.

\section{Clinical consequences of asbestos exposure in mining and milling}

In the present study, the prevalence of respiratory symptoms was relatively low, with most subjects reporting mild dyspnoea. Chronic breathlessness was related to either parenchymal or pleural abnormalities. However, only pleural abnormality was retained in the final model (table 2). In contrast, Lilis and colleagues ${ }^{24}$ found that only combined disorders were predictive of subjective impairment.
Differences in population characteristics, in the extent of radiographic changes, and in the circumstances of exposure (insulators versus miners and millers) may explain these inter-study discrepancies.

A particularly interesting finding was the strong association among all of the respiratory symptoms with objective evidence of lung function impairment (obstructive and restrictive defects). Another important predictor was current or previous cigarette smoking, a finding in keeping with the studies of Quebec chrysotile miners and millers. ${ }^{5621}$ These findings suggest that symptoms, a subjective measure of impairment, are useful outcomes in large epidemiological evaluations of asbestos exposed workers. ${ }^{25-28}$ Whether the reported symptoms can be directly attributed to asbestos exposure, however, remains a topic of controversy. Of interest, is that cumulative exposure was retained in the final models only for dyspnoea, a cardinal symptom of asbestosis (table 2). In addition, the significant effect of smoking in explaining the radiographic abnormalities in the younger workers (group III) (table 2) underscores the importance of establishing active anti-smoking strategies among current asbestos miners and millers in Brazil.

\section{Radiographic changes associated with asbestos mining and milling}

The risk of development of radiographic abnormality was significantly increased in subjects with higher exposure and longer latency (group I) compared to groups II and III (table 3). In addition, the determinants of those outcomes differed significantly between study groups. Thus, the risk of pleural and/or parenchymal abnormalities were increased in group III subjects with a history of smoking and in group II subjects with high levels of cumulative exposure (table 3).

Surprisingly, cumulative exposure did not increase the likelihood of lung function and radiographic abnormalities in group I. This finding was probably related to the homogeneously high level of exposure in these subjects. An alternative explanation may be the presence of tremolite in this mine, independent of the high exposure levels. In addition, we could not rule out the presence of a "survival" effect in the present study-that is, those subjects who were alive at the time of examination would be more resistant to the deleterious effects of asbestos inhalation (see also Study limitations). 


\begin{tabular}{|c|c|c|}
\hline & Logit coefficient (SE) & Odds ratio $(95 \% \mathrm{Cl})$ \\
\hline \multicolumn{3}{|l|}{ Obstructive defect } \\
\hline Parenchymal and pleural abnormalities & $0.79(0.17)$ & $2.20(1.55$ to 3.11$)$ \\
\hline Dyspnoea* ${ }^{*}$ & $0.53(0.10)$ & $1.69(1.39$ to 2.06$)$ \\
\hline Current or past smoking & $0.44(0.09)$ & $1.56(1.30$ to 1.86$)$ \\
\hline Age $>50$ years & $0.42(0.13)$ & $1.52(1.18$ to 1.95$)$ \\
\hline Constant & $-1.96(0.07)$ & \\
\hline \multicolumn{3}{|l|}{ Restrictive defect } \\
\hline Pleural abnormality & $1.18(0.35)$ & 3.27 (1.63 to 6.56$)$ \\
\hline Dyspnoea* ${ }^{*}$ & $0.83(0.21)$ & $2.29(1.51$ to 3.49$)$ \\
\hline Age $>50$ years & $0.32(0.28)$ & $1.38(0.79$ to 2.40$)$ \\
\hline Current or past smoking & $-0.70(0.20)$ & 0.49 (0.33 to 0.74$)$ \\
\hline Constant & $-3.47(0.14)$ & \\
\hline \multicolumn{3}{|c|}{$\begin{array}{l}\text { *MRC questionnaire }{ }^{13} \\
\text { The following variables were considered for model inclusion: age ( }>50 \text { years), radiographic abnormalities, } \\
\text { cumulative exposure ( } \geqslant 10 \text { fibres } / y / c c) \text {, latency ( } \geqslant 20 \text { years), symptoms, and smoking (current or past). }\end{array}$} \\
\hline
\end{tabular}

We were also able to confirm some previous reports that pleural abnormalities per se are associated with respiratory symptoms and lung function impairment. ${ }^{22} 2425$ Although in the past pleural abnormalities, particularly pleural plaques, have often been considered as functionally silent, we found that presence of combined pleural and parenchymal abnormalities were better predictors of impairment than isolated parenchymal abnormalities. Considering that we did not
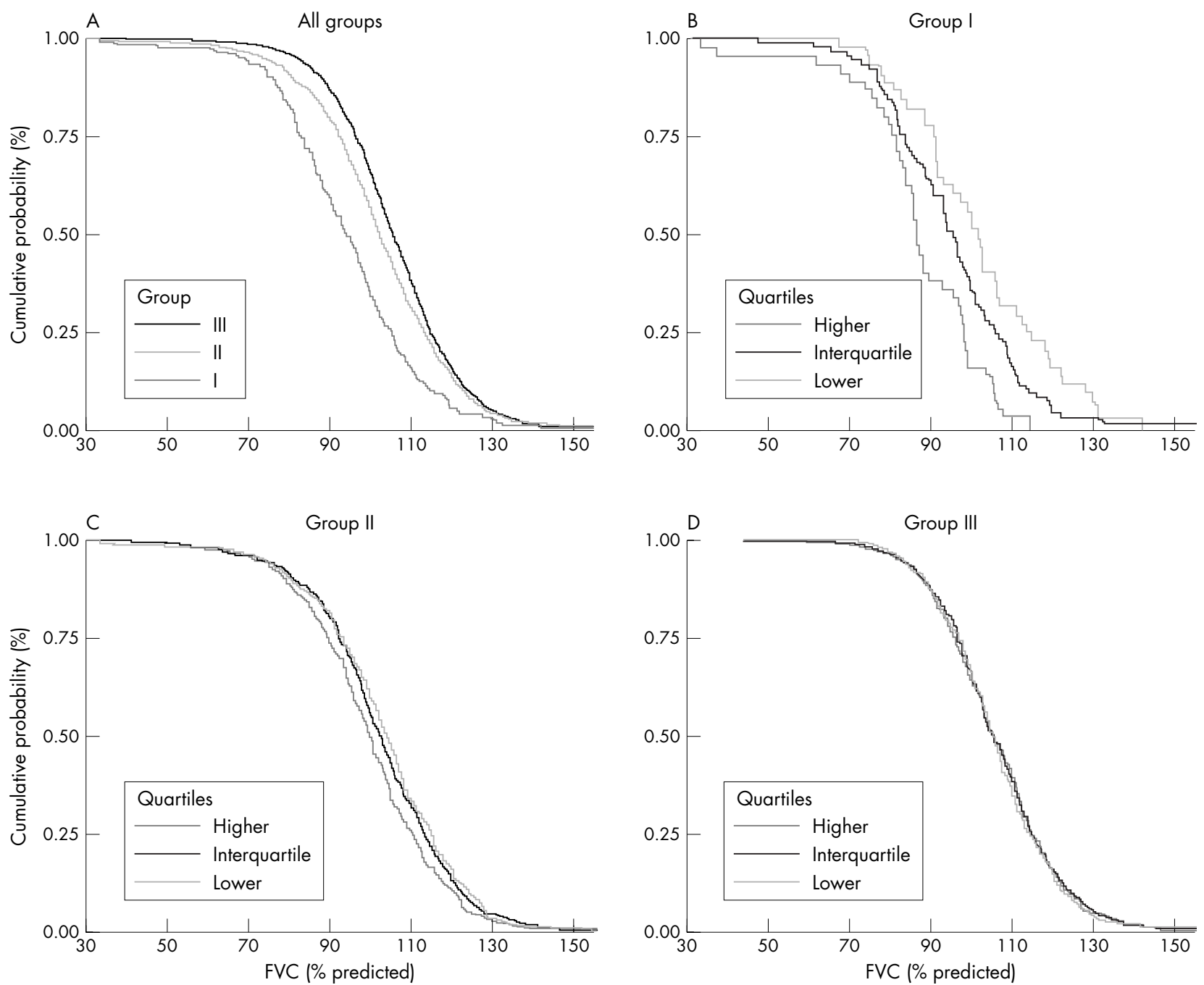

Figure 2 Differences in cumulative probability of individual scores of forced vital capacity (FVC, \% predicted). (A) Inter-group analysis. (B-D) Withingroup effect of cumulative exposure (for groups I, II, and III, respectively). Notes: (A) group I $\times$ III $\left(\chi^{2}=125.18, p<0.00001\right) ;$ group I $\times$ II $\left(\chi^{2}=37.43\right.$, $\mathrm{p}<0.00001)$; group II $\times$ III $\left(\chi^{2}=48.02, \mathrm{p}<0.00001\right)$; (B) upper quartile $\times$ lower quartile $\left(\chi^{2}=4.89, \mathrm{p}=0.0270\right)$; upper quartile $\times$ interquartile range $\left(\chi^{2}=6.72, p<0.0095\right)$; interquartile range $\times$ lower quartile $\left(\chi^{2}=0.10, p>0.05\right)$; (C) upper quartile $\times$ lower quartile $\left(\chi^{2}=9.66, p<0.01\right)$; upper quartile $\times$ interquartile range $\left(\chi^{2}=7.72, p<0.01\right)$; interquartile range $\times$ lower quartile $\left(\chi^{2}=0.84, p>0.05\right)$; (D) Wilcoxon test $(p>0.05)$. 
Table 6 Multiple regression analysis of lung function variables

\begin{tabular}{|c|c|c|c|c|c|c|}
\hline & $\begin{array}{l}\text { Cumulative exposure } \\
\text { (fibres/y/cc) }\end{array}$ & Latency time (years) & Smoking (pack-years) & $\begin{array}{l}\text { Pleural and } \\
\text { parenchymal } \\
\text { abnormalities }\end{array}$ & Constant & $\mathrm{R}^{2}$ (SEE) \\
\hline FVC (\% pred) & $-0.0161(0.006)$ & $-0.260(0.025)$ & NS & $-6.599(1.276)$ & $110.36(0.72)$ & $0.04(15.8)$ \\
\hline $\mathrm{FEV}_{1}(\%$ pred $)$ & NS & $-0.232(0.034)$ & $-0.0537(0.013)$ & $-9.310(1.347)$ & $104.9(0.72)$ & $0.05(16.7)$ \\
\hline $\mathrm{FEV}_{1} / \mathrm{FVC}(\%)$ & NS & $-0.196(0.003)$ & $-0.0128(0.001)$ & $-0.485(0.127)$ & $85.7(0.07)$ & 0.04 (12.3) \\
\hline $\mathrm{FEF}_{25-75 \%}(\%$ pred) & NS & NS & $-0.0711(0.028)$ & -11.678 (3.098) & $85.2(0.73)$ & $0.57(7.0)$ \\
\hline
\end{tabular}

$\mathrm{R}^{2}$, coefficient of determination; SEE, standard error of the estimate; NS, non-significant.

$(-)$ indicates that the independent variable did not remain in the final model.

differentiate pleural plaques from diffuse pleural thickening, we could not identify the precise structural basis of these intriguing findings.

\section{Lung function findings}

In our study, lung function indexes in group I and II subjects were consistently lower than in group III subjects (fig 2A)although most subjects did not present abnormal tests results (at least as assessed by mean values expressed as \% of predicted). This was also true when we considered the quartiles of exposure and latency time (fig 2B-D). Recently, Algranti and co-workers, ${ }^{30}$ using a similar approach, also found a significant effect of exposure on lung function levels in Brazilian asbestos-cement workers. These data highlight the relevance of analysing large epidemiological data using more sensitive statistical procedures to unravel the effects of exposure on lung function. ${ }^{19}$

Interestingly, we found parenchymal and pleural abnormalities to be associated with an obstructive ventilatory defect, independent of smoking (table 5). We interpret these results as indication that increased dust exposure-as suggested by higher prevalence of pleural plaques-can be related to airways disease. In fact, studies involving a large cohort of Canadian miners and millers found a substantial increase in "bronchitis" with chrysotile exposure and smoking.45 Moreover, Kilburn and Warshaw ${ }^{27}$ found evidences of airflow limitation and air trapping 20 years after the cessation of exposure in asbestos workers who never smoked. Whether this can be directly attributed to asbestos fibres (due to peribronchiolar infiltrates and/or fibrosis-that is, asbestos small airways disease), the level of non-specific dust or other contaminants remains to be determined.

\section{Study limitations}

The retrospective nature of the exposure evaluation and the chronological definition of the study groups implied that age and latency time-two well-known confounding factorswere dissimilar among the three groups. Thus, group III subjects were younger and presented with lower latency time than their counterparts of groups I and II (table 1). However, at the time of the present evaluation, more than half of group III workers already had a latency time of at least 20 years. In fact, a post hoc analysis with the subjects grouped according to equivalent latency times showed that group I subjects had higher prevalence of radiographic abnormalities than group II; in addition, group III subjects presented with less abnormalities than group II workers with similar latency (table 4). Considering, however, that there have been reports of a significant longitudinal decline in lung function in other asbestos exposed workforces, ${ }^{10} 3132$ prospective evaluations of the present study population should be undertaken to improve the inter-group comparability.

While ideally a reference (non-exposed) population should have been studied in parallel with the present study population, in practice identification of such a reference population is difficult because of the "healthy" worker effect.
In fact, the study design also means that this phenomenon could not be ruled out as a cause of selection bias: we were unable to evaluate $35.9 \%$ of the target population, particularly in group I. In this context, it should be recognised that the impact of a survival effect would be more prominent in this group which have been more heavily exposed to asbestos (table 1). Therefore, we may have even underestimated the true prevalence of radiographic abnormalities in the older workers.

Also important is that asbestos exposure in the older groups was estimated using a subjective method. Therefore, we cannot rule out that these workers may have overestimated the degree of dustiness in their workplace, though photographic records support their estimates. We may also have underestimated the prevalence of morphological and functional abnormalities since the more sensitive imaging and lung function techniques were not used (for example, high resolution computed tomography and lung diffusion capacity).

Unfortunately, we were also unable to assess the asbestos related mortality in this sample: death certificates are notoriously imprecise in remote areas of Central Brazil and there was no systematic recording of the whereabouts of the ex-workers. Finally, it is important to emphasise that our results should not be extrapolated for asbestos related malignant disease.

\section{Conclusions}

We conclude that improvements over time in workplace conditions are associated with a significant decrease in the risk of non-malignant abnormalities in Brazilian chrysotile asbestos miners and millers. Our data are particularly relevant for developing countries where asbestos extraction is performed on a large scale and healthcare resources are scarce. The present results, however, should be further confirmed in prospective and controlled studies, including in the present study population.

\section{ACKNOWLEDGEMENTS}

The authors would like to thank: Drs John C McDonald (National Heart and Lung Institute, London, UK), Michel Camus (Health Canada), Andre Dufresne and Bruce Case (Department of Epidemiology, Biostatistics and Occupational Health, McGill University, Montreal, Canada), and John E Parker (West Virginia University, Respiratory Division, Morgantown, VA, USA) for their intellectual input throughout the study. The authors are also indebted to Drs Nestor Muller (Department of Radiology, University of British Columbia, Vancouver, Canada), Eduardo Algranti (Divisao de Medicina do Trabalho, Fundacentro, Sao Paulo, Brazil), and Eduardo De Capitani (Disciplina de Pneumologia, FCM-UNICAMP, Sao Paulo, Brazil) for their helpful assistance on the chest $x$ ray analysis. They would also wish to thank Dr Miriam CB Oliveira (Institute for Technological Research, Sao Paulo, Brazil) for performing the mineralogical analysis. Finally, we are grateful to Dr Jose Trad Neto (UNICAMP, Brazil) and Mrs Lara Napolis (UNIFESP-EPM, Brazil) for their work during the different phases of the project. 


\section{Authors' affiliations}

E Bagatin, S Kitamura, M Favero, D C Moreira-Filho, Area of Occupational Health, State University of Campinas (UNICAMP), Campinas, SP, Brazil, and Jundiai School of Medicine, Jundiai, SP, Brazil

J A Neder, L E Nery, A Sette, Pulmonary Function and Clinical Exercise Physiology Unit (SEFICE), Division of Respiratory Diseases, Federal University of Sao Paulo (UNIFESP), São Paulo, SP, Brazil

M Terra-Filho, Division of Respiratory Diseases, University of Sao Paulo (USP), São Paulo, SP, Brazil

J Kavakama, Department of Radiology, USP, São Paulo, SP, Brazil A Castelo, Division of Infectious Diseases, UNIFESP, São Paulo, SP, Brazil

V Capelozzi, Department of Pathology, USP, São Paulo, SP, Brazil R Tavares, Department of Radiology, UNIFESP, São Paulo, SP, Brazil C Peres, Department of Preventive and Social Medicine, UNIFESP, São Paulo, SP, Brazil

M R Becklake, Respiratory Epidemiology and Clinical Research Unit, Department of Epidemiology, Biostatistics and Occupational Health, McGill University, Montreal, QC, Canada

Supported by a Research Grant from FAPESP-Brazil (1996/10415-6). Competing interests: EB, LEN, and MTF received support from SAMA (Institutional Grant to State University of Campinas, no. 2P-04559-98) for travelling and lodging to data collection in the mines and also to attend international conferences. EB, LEN, and MTF have a healthcare company which performs disability and medicolegal evaluations in occupational lung diseases: SAMA is one of their clients.

$M$ Favero is deceased

\section{REFERENCES}

1 United States Department of Health and Human Services. Asbestosis, National Institute for Occupational Safety and Health Publications. Cincinnati, $\mathrm{OH}$ : Division of Standards Development and Technology Transfer Publications, 1992.

2 Dement JM, Merchant JA, Green FHI. Asbestosis. In: Merchant JA, ed. Occupational respiratory diseases. DHHS (NIOSH) Publication No. 86-102. Washington, DC: US Government Printing Office, 1986

3 Becklake MR. The epidemiology of asbestosis. In: Liddell D, Miller K, eds. Mineral fibers and health. Boca Raton, FL: CRC Press, 1991:103-19.

4 Becklake MR, Fournier-Massey G, Rossiter CE, et al. Lung function in chrysotile asbestos mine and mill workers of Quebec. Arch Environ Health 1972;24:401-9.

5 McDonald JC, Becklake MR, Fournier-Massey G, et al. CE. Respiratory symptoms in chrysotile asbestos mine and mill workers of Quebec. Arch Environ Health 1972;24:358-63.

6 McDonald JC, Becklake MR, Gibbs GW, et al. The health of chrysotile asbestos mine and mill workers of Quebec. Arch Environ Health 1974;28:61-8.

7 Liddell D, Eyssen G, Thomas D, et al. Radiological changes over 20 years in relation to chrysotile exposure in Quebec. In: Walton WH, ed. Inhaled particles IV. Oxford: Pergamon Press, 1975:799-813.

8 Selikoff IJ. Clinical survey of chrysotile asbestos miners and millers in Baie Verte, Newfoundland-1976. Report to the National Institute of Environmental Health Sciences, 1977.

9 Enarson DA, Embree V, Maclean L, et al. Respiratory health in chrysotile asbestos miners in British Columbia; a longitudinal study. $\mathrm{Br} J$ Ind Med 1988;45:459-63.

10 Schwartz DA, Davis CS, Merchant JA, et al. Longitudinal changes in lung function among asbestos-exposed workers. Am J Respir Crit Care Med 1994; 150:1243-9.
11 Oliveira MCB, Coutinho JMV. Petrography and mineralogical analysis of asbestos fibers from Vila Nova Amianto, Bahia, Brazil, Institute for Technological Research Report No. 42. 1999:409.

12 Oliveira MCB, Frazao EB, Valarelli JV, et al. Technological characteristics of the serpentines in the Cana Brava Mine, GO, Brazil. Proceedings of the International Simposium on Mine Planning and Equipment. Rotterdam: A. A. Balkema, 1997:77-80.

13 Medical Research Council's Committee on Research into Chronic Bronchitis. Questionnaire on Respiratory Symptoms. London: Medical Research Council, 1966.

14 Kitamura S, Chou A, Moreira DC, et al. Criteria to estimate the overall exposure to asbestos fibers among asbestos mining workers in Brazi [abstract]. Proceedings of the International Conference on Occupational and Environmental Health in the Chemical Industry. Vienna, Austria, 1999.

15 US Department of Health and Human Services. NIOSH manual of analytical methods, DHHS Publication No. 84-100. Washington, DC: US Government Printing Office, 1984

16 International Labor Office. Guidelines for the use of ILO international classification of radiographs of pneumoconiosis. Geneva: ILO, 1980.

17 American Thoracic Society. Standardization of spirometry, 1994 update. Am J Respir Crit Care Med 1995;152:1107-36.

18 Pereira CAC, Barreto SP, Simões JG, et al. Valores de referência para espirometria em uma amostra da população brasileira adulta. J Pneumo 1992;18:10-22.

19 Tornling G, Johard U. How to present lung function data in epidemiological studies? In: Chiyotani K, Hosoda Y, Aizawa Y, eds. Advances in the prevention of occupational respiratory diseases. Amsterdam: Elsevier, 1998:452-5.

20 Kleinfield M, Messite J, Shapiro J. Clinical, radiological, and physiological findings in asbestosis. Arch Intern Med 1966;117:813-19.

21 Becklake MR, Foumier-Massey G, Rossiter CE, et al. Lung function in chrysotile asbestos mine and mill workers of Quebec. Arch Environ Health 1972;24:401-9.

22 Hilt B, Lien JT, Lund-Larsen PG. Lung function and respiratory symptoms in subjects with asbestos-related disorders: a cross-sectional study. Am J Ind Med 1987; 11:517-28

23 Chen CR, Chang Hy, Suo J, et al. Occupational exposure and respiratory morbidity among asbestos workers in Taiwan. J Formos Med Assoc 1992;91:1138-42.

24 Lilis R, Miller A, Godbold J, et al. Radiographic abnormalities in asbestos insulators: effects of duration from onset of exposure and smoking. Relationships of dyspnea with parenchymal and pleural fibrosis. Am J Ind Med 1991;20:1-15.

25 Brodkin CA, Barnhart S, Anderson G, et al. Correlation between respiratory symptoms and pulmonary function in asbestos-exposed workers. Am Rev Respir Dis 1993:148:32-7.

26 Rosenstock L, Barnhart S, Heyer NJ, et al. The relation among pulmonary function, chest roentgenographic abnormalities, and smoking status in an asbestos-exposed cohort. Am Rev Respir Dis 1988;138:272-7.

27 Kilburn KH, Warshaw RH. Airways obstruction from asbestos exposure. Effects of asbestosis and smoking. Chest 1994;106:1061-70.

28 Miller A, Lilis R, Godbold J, et al. Spirometric impairments in long-term insulators. Relationships to duration of exposure, smoking, and radiographic abnormalities. Chest 1994;105:175-82.

29 Broderick A, Fuortes U, Merchant JA, et al. Pleural determinants of restrictive lung function and respiratory symptoms in an asbestos-exposed population. Chest 1992;101:684-91.

30 Algranti E, Mendonça EM, DeCapitani EM, et al. Non-malignant asbestosrelated diseases in Brazilian asbestos-cement workers. Am J Ind Med 2001;40:240-54.

31 Siracusa A, Forcina A, Volpi R, et al. An 11-year longitudinal study of the occupational dust exposure and lung function of polyvinyl chloride, cement and asbestos cement factory workers. Scand J Work Environ Health 1988;14:181-8.

32 Rom WN. Accelerated loss of lung function and alveolitis in a longitudinal study of non-smoking individuals with occupational exposure to asbestos. Am J Ind Med 1992;21:835-44. 